\title{
Results on laboratory-instrumental studies of atmospheric air after fire suppression
}

\author{
V. E. Kriyt ${ }^{1, *}, Y u$. N. Sladkova ${ }^{1}, M . V$. Sannikov ${ }^{2}$, and $A$. O. Pyatibrat ${ }^{3}$ \\ ${ }^{1}$ North-West Public Health Research Center of Rospotrebnadzor, 2nd Sovetskaya st., 4, 191036 St. \\ Petersburg, Russia \\ ${ }^{2}$ All-Russian Center for Emergency and Radiation Medicine named after A.M. Nikiforova, Ministry \\ of Emergency Situations of Russia, 4/2 Academician Lebedeva st., 194044 St. Petersburg, Russia \\ ${ }^{3}$ St. Petersburg State Pediatric Medical University, 2 Litovskaya st., 194100 St. Petersburg, Russia
}

\begin{abstract}
The paper presents the results of laboratory-instrumental studies of atmospheric air sampled during the first day after fire suppression in different localization. Carbon oxide, hydrochloride, hydrocyanide, nitrogen oxides, sulfur dioxide, and dioxins were determined in the air samples taken. The comparison was made with the hygienic standards established by SanPiN 1.2.3685-21 "Hygienic standards and requirements to ensure safety and (or) harmlessness for humans of environmental factors". Analysis of the obtained data showed that the concentrations of most of the detected toxic combustion products one day after fire suppression were at a level close to MAC for the working area air, but significantly exceeded MAC established for the atmospheric air of urban and rural settlements. The largest exceedances were obtained at sites such as industrial and residential buildings, which can be explained by the use of a wide range of building materials.
\end{abstract}

\section{Introduction}

Atmospheric air is a mixture of gaseous chemical substances of natural and man-made origin. One of the significant sources of atmospheric air pollution, along with the industrial sector of the economy and road transport, are fires [13]. In fires, concentrations of pollutants many times exceed the normative values regulated by sanitary legislation, and their reduction is associated with the reform of a wide range of sectors of the economy and human life. One of the greatest hazards are toxic products of combustion, which should be understood as substances of various aggregate states and compounds formed as a result of oxidation process with the release of significant amounts of thermal energy.

The component composition of combustion products in the air in a fire depends on substances subjected to oxidation process, as well as on conditions of their combustion [1]. The oxygen content plays the main role in combustion process. According to the Methodical Recommendations, in fires in buildings, the reduction of oxygen to $16 \%$ occurs within $2-3$ minutes, which leads mainly to the formation of incomplete combustion products, among which the leading place is taken by carbon monoxide [14].

\footnotetext{
*Corresponding author: v.kriit@s-znc.ru
} 
In accordance with Art. 9 of the Federal Law dated July 22, 2008, No. 123-FZ, reduced oxygen concentration refers to one of the dangerous factors of fire, the evaluation criteria for which are presented in GOST 12.1.004-91 $[15,16]$. Thus, the criterion for evaluating the reduced oxygen concentration is the maximum permissible value $-0.226 \mathrm{~kg} / \mathrm{m}^{3}$ [17] .

In addition, in fires in confined spaces (especially in residential and public buildings), the process of destruction is mainly exposed to finishing materials and household items, can emit substances such as, for example, acrolein (its source can be polypropylene, cellulose, acrelane (used for carpets)), hydrocyanic acid, which is a strong poison and is formed by combustion of nylon and polyurethane, as well as resins, acrylonitrile, paper, polyamine rubber, etc. [2]. According to the literature, combustion products from fire can contain up to 400 different compounds [3], which places special demands on the development of fire-safe polymeric materials [4], as well as on the control of the use of new and existing finishing materials and decorative items in enclosed (confined) spaces.

Low-temperature fires with temperatures up to $600^{\circ} \mathrm{C}$ can be identified as a separate group of fires. They are characterized by the release into the air of a complex complex of chemicals, including dioxins and dioxin-like compounds, which are dangerous in any concentration [5, $6]$.

It should be noted that concentrations of such substances as benzene, vinyl chloride, nitrogen oxide, sulfur dioxide, hydrogen cyanide (hydrocyanide), chloroform, hydrogen chloride (hydrochloride), carbon oxide, formaldehyde in the surface air in fires exceed MAC in $60-100 \%$ of cases [7]. Carbon monoxide, formaldehyde, nitrogen dioxide, benzene and toluene are the most dangerous components with the effect of complex or combined action [8].

\section{Materials and Methods}

In order to assess concentrations of toxic combustion products, single air samples were taken and analyzed during the first day after liquidation of 56 fires of different localization (at industrial, residential, agricultural and forest sites), using both express methods with the use of portable gas analyzers and classical methods with aspirators.

Carbon monoxide, hydrochloride, hydrocyanide, nitrogen oxides, sulfur dioxide, and dioxins were determined in the taken air samples. The comparison was made with the hygienic standards established by SanPiN 1.2.3685-21 [18].

In the testing laboratory, the analysis of selected one-time samples of atmospheric air was carried out using the methods of gas chromatography (gas chromatographic separation), as well as quantitative mass spectrometry (GC-MS) by their sequential use (connecting the separating column of the chromatograph and the ion source of the mass spectrometer) $[9,10]$.

\section{Results and Discussion}

Studies were conducted on 6 substances of generally toxic and pulmonotoxic effects, which are most frequently encountered in fires of different localization. Among these substances, it is necessary to highlight carbon monoxide, which is formed in almost all cases of combustion of carbon-containing materials, especially under conditions of oxygen deficiency $[3,11]$. The choice of the substances to be determined was also influenced by the possibility of enhancing the toxic effect when combining the typical representatives of destruction products: carbon monoxide and nitrogen dioxide, carbon monoxide and hydrocyanide, as well as the complex effects of exposure to nitrogen dioxide and hydrocyanide [3].

The inclusion of dioxins in the list of analyzed indicators is related to the fact that despite the main source of dioxin intake into the human body with food (up to 95\%) and the low 
level of its intake with air (3.5\%), dioxins have the potential to contaminate the entire human food chain [19]. In addition, dioxins are extremely slowly eliminated from the body, their half-life from the body is 10 years or more, have a general toxic effect, have a cytotoxic effect, cause distant effects associated with immunosuppressive, mutagenic, teratogenic, embryotoxic and carcinogenic properties [12].

The results of laboratory-instrumental studies of single atmospheric air samples for carbon monoxide, hydrochloride, hydrocyanide, nitrogen oxides, sulfur dioxide and dioxins during the first day after fire suppression of different localization are presented in Table 1.

Table 1. Results of studies of the air environment during the first day after the fire suppression by individual chemicals, $\mathrm{mg} / \mathrm{m}^{3}$

\begin{tabular}{|c|c|c|c|c|c|c|}
\hline \multirow{2}{*}{ Objects } & \multicolumn{6}{|c|}{ Average one-time concentration of chemicals, $\mathrm{mg} / \mathrm{m}^{3}$} \\
\hline & $\mathrm{CO}$ & $\mathrm{HCl}$ & $\mathrm{HCN}$ & $\mathrm{N}_{\mathrm{x}} \mathrm{O}_{\mathrm{x}}$ & $\mathrm{SO}_{2}$ & Dioxins \\
\hline Industrial enterprises & $31.2 \pm 0.5$ & $10.2 \pm 0.6$ & $0.8 \pm 0.2$ & $5.4 \pm 0.2$ & $24.3 \pm 1.4$ & $(7.6 \pm 0.8) \times 10^{-9}$ \\
\hline $\begin{array}{l}\text { Residential buildings and } \\
\text { household buildings and }\end{array}$ & $24.5 \pm 0.3$ & $8.5 \pm 0.3$ & $0.6 \pm 0.1$ & $6.2 \pm 0.3$ & $17.5 \pm 0.5$ & $(3.4 \pm 0.7) \times 10^{-9}$ \\
\hline Agricultural objects & $16.7 \pm 0.4$ & $7.2 \pm 0.4$ & $0.4 \pm 0.1$ & $2.2 \pm 0.2$ & $14.5 \pm 0.6$ & $(9.4 \pm 1.2) \times 10^{-10}$ \\
\hline Forest objects & $14.4 \pm 0.8$ & $6.3 \pm 0.5$ & $0.3 \pm 0.1$ & $3.1 \pm 0.1$ & $9.5 \pm 0.4$ & $(7.2 \pm 0.7) \times 10^{-10}$ \\
\hline $\begin{array}{l}\text { Maximum one-time } \\
\text { MAC in air of working } \\
\text { area, } \mathrm{mg} / \mathrm{m}^{3}\end{array}$ & $20^{\#}$ & 5 & 0.3 & $\begin{array}{l}5^{*} / \\
2^{* *}\end{array}$ & 10 & - \\
\hline $\begin{array}{l}\text { Maximum one-time } \\
\text { MAC in atmospheric air } \\
\text { of urban and rural } \\
\text { settlements, } \mathrm{mg} / \mathrm{m}^{3}\end{array}$ & 5.0 & 0.2 & - & $\begin{array}{l}0.2^{* *} / \\
0.4^{* * *}\end{array}$ & 0.5 & - \\
\hline $\begin{array}{l}\text { Average daily MAC in } \\
\text { atmospheric air of urban } \\
\text { and rural settlements, } \\
\mathrm{mg} / \mathrm{m}^{3}\end{array}$ & 3.0 & 0.1 & 0.01 & $0.1^{* *} /-^{* * *}$ & 0.05 & $0.5 \mathrm{pg} / \mathrm{m}^{3}$ \\
\hline $\begin{array}{l}\text { Average annual MAC in } \\
\text { atmospheric air of urban } \\
\text { and rural settlements, } \\
\mathrm{mg} / \mathrm{m}^{3}\end{array}$ & 3.0 & 0.02 & - & $\begin{array}{l}0.04^{* *} / \\
0.06^{* * *}\end{array}$ & - & - \\
\hline
\end{tabular}

\# MAC for carbon monoxide can be increased with a duration of operation in an atmosphere containing carbon monoxide, no more than 1 hour - up to $50 \mathrm{mg} / \mathrm{m}^{3}$, no more than $30 \mathrm{~min}$. - up to $100 \mathrm{mg} / \mathrm{m}^{3}$, no more than $15 \mathrm{~min} .-200 \mathrm{mg} / \mathrm{m}^{3}$ Repeated work in conditions of high levels of carbon monoxide in the air of the working area can be carried out with a break of at least 2 hours; * Of nitrogen oxides in terms of $\mathrm{NO}_{2} ; * *$ Nitrogen dioxide; $* * *$ Nitrogen (II) oxide.

It should be noted that in the Russian Federation, there is no standardization of dioxins in the air of working area, the maximum occupational exposure to TCDD, equal to $200 \mathrm{pg} / \mathrm{m}^{3}$ of the air in working area with a temporary load of 8 hours, is proposed only in the guidelines of MR 2.2.9.0056-11 [20 ]. Roughly for evaluating the results obtained, the rate of $0.1 \mathrm{ng}$ $\mathrm{TEQ} / \mathrm{Nm}^{3}$ at $11 \% \mathrm{O}_{2}$ can be applied [21].

The analysis of the data obtained, presented in Table 1, indicates that during the first days after the elimination of the fire, the concentrations of most of the detected toxic combustion products were at a level close to MAC for the air of the working area, but significantly exceeding MAC established for the atmospheric air of urban and rural settlements. The 
largest exceedances were obtained at such sites as industrial and residential buildings, which can be explained by the use of a large number of polymer construction materials.

\section{Conclusions}

1. The obtained data confirm the need to develop methodological approaches to laboratory and instrumental control of building materials at all stages of construction and operation of facilities.

2. Although the gastrointestinal tract is the main route of entry of dioxins into the human body, when their high concentrations in the atmospheric air at all stages of fire suppression, it is necessary to consider their entry through the respiratory organs.

\section{References}

1. E. V. Chernushevich, P. V. Shirinkin, Siberian fire and rescue bulletin, 1(16), 2228 (2020)

2. S. Kh. Sarmanaev, V. A. Basharin, P. G. Tolkach, K. A. Sherbashov, Russian biomedical journal, 16(2), 434-442 (2015)

3. V. A. Basharin, A. N. Grebenyuk, N. F. Markizova, T. N. Preobrazhenskaya, S. Kh. Sarmanaev, P. G. Tolkach, Military medical journal, 336(1), 22-28 (2015)

4. N. V. Ermakova, Electronic scientific journal of Kursk State University, 3(15), 104-107 (2017)

5. V. S. Rukavishnikov, I. V. Kolycheva, V. B. Dorogova, L. A. Budarina, Bulletin VSNTS SB RAMS, 2(40), 7-14 (2005)

6. G. A. Sofronov, V. S. Rumak, N. V. Umnova, D. A. Belov, K. A. Turbabina, Medical academic journal, 16(3), 7-18 (2016)

7. I. V. Kolycheva, Bulletin VSNTS SB RAMS, 8(46), 133-139 (2005)

8. V. S. Rukavishnikov, I. V. Kolycheva, Occupational medicine and industrial ecology, 6, $1-5(2007)$

9. V. E. Kriyt, Yu. N. Sladkova, M. V. Sannikov, Pyatibrat A.O. Occupational medicine and industrial ecology, 8(60), 494-501 (2020)

10. V. E. Kriyt, Yu. N. Sladkova, M. V. Sannikov, A. O. Pyatibrat, Public health and habitat, 10(331), 65-74 (2020).

11. N. V. Martinovich, I. N. Tatarkin, A. V. Antonov, Scientific-analytical journal bulletin of the St. Petersburg University of the State Fire Service of the Ministry of Emergency Situations of Russia, 2, 1-6 (2014)

12. G. A. Sofronov, V. R. Rembovsky, A. S. Radilov, L. A. Mogilenkova, Medical academic journal, 19(1), 17-28 (2019).

13. Air quality guidelines for Europe (Second Edition), Published on behalf of the World Health Organization Regional Office for Europe, 312 (Publishing house "Ves Mir", 2004).

14. A. N. Grebenyuk, V. A. Basharin, N. F. Markizova, T. N. Preobrazhenskaya, Methodical recommendations for the provision of medical assistance to personnel in case of damage by combustion products, 32 (GVMU MO RF, 2011)

15. Federal Law dated July 22, 2008 No. 123-FZ "Technical Regulations on Fire Safety Requirements"

16. GOST 12.1.004-91 "Fire safety. General requirements" 
17. Order of the Ministry of Emergency Situations of the Russian Federation dated June 30, 2009 No. 382 "On approval of the methodology for determining the calculated values of fire risk in buildings, structures and structures of various classes of functional fire hazard"

18. SanPiN 1.2.3685-21 "Hygienic standards and requirements for ensuring the safety and (or) harmlessness of environmental factors for humans", approved by the Decree of the Chief State Sanitary Doctor of the Russian Federation No. 2 dated January 28, 2021.

19. Air quality guidelines for Europe (Second Edition). Published on behalf of the World Health Organization Regional Office for Europe. - M.: Ves Mir Publishing House, 2004 $-312 \mathrm{p}$.

20. MR 2.2.9.0056-11 "Preventive measures at dioxin-hazardous industries"

21. Guidelines for the identification and quantification of emissions of dioxins, furans and other unintentionally produced POPs under Article 5 of the Stockholm Convention, January 2013 